Original Article

Running Author:

Running Title:

\title{
Getting Obligations Right: Autonomy and Shared Decision Making
}

Jonathan Lewis 1

Email jonathan.lewis@dcu.ie

$\mathrm{AQ1}$

AQ2

1 Institute of Ethics, School of Theology, Philosophy and Music, Faculty of Humanities and Social Sciences, Dublin City University, S103, Senior House, All Hallows Campus, Dublin 9, Ireland

\section{ABSTRACT}

Shared Decision Making ('SDM') is one of the most significant developments in Western health care practices in recent years. Whereas traditional models of care operate on the basis of the physician as the primary medical decision maker, SDM requires patients to be supported to consider options in order to achieve informed preferences by mutually sharing the best available evidence. According to its proponents, SDM is the right way to interpret the clinician-patient relationship because it fulfils the ethical imperative of respecting patient autonomy. However, there is no consensus about how decisions in SDM contexts relate to the principle of respect for autonomy. In response, I demonstrate that in order to make decisions about what treatment they will or will not receive, patients will be required to meet different conditions depending on the approach proponents of SDM take to understanding personal autonomy. Due to the fact that different conceptions of autonomy yield different obligations, I argue that if physicians and patients satisfied all the conditions described in standard accounts of SDM, then SDM would undermine patient autonomy.

\section{Introduction}

'No decision about me without me'. ${ }^{1}$ This is the National Health Service's key maxim for its Shared Decision Making ('SDM') agenda, which, like those adopted by the respective health services of Australia, Canada, France, Germany, Italy, the Netherlands, Spain, Switzerland and the US, aims to revise the traditional view of the physician as the primary decision maker in clinical contexts. Commentators claim that SDM goes further than informed consent by facilitating a decision-making process whereby both patient and physician share expert information; the physician describes the probable benefits and potential harms of treatment options; the patient expresses their values and preferences. ${ }^{2}$

There is a certain amount of consensus regarding the essential conditions of SDM practices. ${ }^{3}$ Specifically, proponents claim that SDM involves, on the one hand, physicians offering treatment options and describing probable benefits and potential harms. On the other hand, patients are required to communicate their values and preferences. Taking into account the information 
provided by the patient, phvsicians are required to present their recommendations before executing a specific decision. ${ }^{4}$ For the purposes of this article, I will refer to this as a standard account of SDM.

Although SDM is in its clinical infancy, and although there is a general lack of clarity regarding its practical and ethical implications, what we can infer from patient support material, policy documents and the medical literature is that SDM has developed in response to debates in medical ethics. A number of commentators have suggested that SDM is the right way to interpret the clinician-patient relationship because it is perceived to fulfil the ethical imperative of respecting patient autonomy. ${ }^{5}$ Glyn Elwyn and his co-authors argue that by encouraging patients to reflect on the benefits and harms of proposed treatments so that they communicate their preferences, SDM 'respects patient autonomy and promotes patient engagement' ${ }^{6}$ Furthermore, even though SDM has received relatively limited attention in the bioethical literature, a number of medical ethicists have suggested that SDM has been clinically motivated, in part, by the perception that it respects patient autonomy by promoting patient autonomy. ${ }^{7}$ According to John Wennberg, the provision of 'decision aids', which have become routine tools to support patient involvement in decisions, ${ }^{8}$ are the key mechanisms for promoting patient autonomy. ${ }^{9}$ Peter Ubel, Karen Scherr and Angela Fagerlin have argued that an essential feature of SDM is 'patient empowerment', a concept that they equate with autonomy promotion. ${ }^{10}$ In addition, Lisa Dive has argued for processes that go beyond mere communication of information to patients, processes that enhance a patient's capacity to be autonomous. ${ }^{11}$

When it comes to standard accounts of the principle in medical ethics, respect for autonomy is sometimes invoked in the context of informed consent and, at other times, when discussing choice of treatment. What this shows is that considerations of respect for autonomy tend to focus on situations in which decisions need to be made about what interventions patients will or will not receive. ${ }^{12}$ However, it is unclear how SDM is meant to respect patient autonomy. Elwyn and colleagues, for example, argue that SDM 'rests on accepting that individual self-determination is a desirable goal and that clinicians need to support patients to achieve this goal, wherever feasible', which means 'that individuals are [not] abandoned' but supported by 'building good relationships, respecting both individual competence and interdependence on others'. ${ }^{13}$ Similarly, Ubel and his co-authors claim that SDM 'respects patient autonomy by involving patients in their health care choices without forcing them to feel like they are making the decision by themselves'. ${ }^{14}$ Both Elwyn, Ubel and their respective co-authors seem to understand autonomy as a property or capacity of persons such that individuals are able to competently reflect on their values, desires and motives, to make decisions based on these values, desires and motives and to have their value- and preference-based choices respected. However, Ubel and his colleagues also claim that patients are autonomous in the sense that it is their right to 'have the final say about those choices'. ${ }^{15}$ Dive has argued against Ubel's right-oriented account of autonomy, claiming that 'if the emphasis is on enhancing patients' autonomy, then the challenge is rather to elucidate each individual patient's preferences and goals, and to present the information about treatment options in relation to those goals'. ${ }^{16}$ Elsewhere, Anne Donchin has argued for a more value-oriented, relational conception of autonomy, emphasising the interpersonal dimension of the physician-patient relationship and the complex power relations that constitute that relationship and which affect patient autonomy. ${ }^{17}$

Bearing in mind that SDM challenges the idea that the physician is the primary decision maker, one might assume that it is the patient who is ultimately responsible for making the decision about treatment choices. However, the notion of shared decision making confuses matters. ${ }^{18}$ Does it mean that the process leading up to the decision is shared with the physician making the 
final decision? Does it mean that the process leading up to decision is shared with the patient making the final decision? Or does it just mean that the process leading up to the decision is shared? Despite general agreement that SDM is meant to respect patient autonomy, there appears to be no consensus about how the 'sharedness' of the decision-making process relates to the culminating decision. According to one approach, a necessary condition of SDM is a voluntary patient decision. ${ }^{19}$ By contrast, others consider the decision itself to be shared, consisting of mutual agreement. ${ }^{20} \mathrm{~A}$ third approach considers the final decision to be the responsibility of the physician. ${ }^{21}$ Other approaches are less obvious. Some state that patients should be supported to be 'involved' in the decision-making process. ${ }^{22}$ Others claim that SDM is meant to aid patients in developing and communicating 'informed preferences'. ${ }^{23}$

If SDM is to respect patient autonomy, then it does matter who, ultimately, makes the decision about what treatment a patient will or will not receive. Following a brief sketch of four principal categories of autonomy $(\S 2)$, the subsequent section ( $\$ 3)$ demonstrates that the question of whether a physician is obligated to respect a patient's decision is conditional on the approach proponents of SDM take to understanding personal autonomy. The following section (§4) shows that different approaches to autonomy yield different obligations. The problem facing proponents of SDM is that respect for the conceptions of autonomy considered here yields obligations that are not amenable to standard accounts of the requirements of SDM. What this shows is that even though there may be other reasons that justify the decision-making conditions described in standard accounts of SDM, such as reasons concerning beneficence and harm, the quality of patient experiences, health outcomes, risk and national legislation. these conditions conflict with obligations generated by the principle of respect for autonomy. ${ }^{24}$ On the one hand, certain obligations generated by respect for autonomy have not been captured by standard accounts of SDM. On the other hand, I argue that if physicians and patients satisfied all the conditions described in the standard account of SDM considered here, then SDM would undermine patient autonomy.

\section{Four Approaches to Autonomy in Medical Ethics}

Recognition of the vulnerability of autonomy in health care contexts led to the inclusion of respect for autonomy as a key concern in biomedical ethics, one that has an intrinsic value that cannot be conflated with the value of a patient's wellbeing (though, in concrete circumstances, the principle of respect for autonomy is rarely considered in isolation from those principles more directly associated with well-being $\left.{ }^{25}\right) .{ }^{26}$ In debates about medical decisions, four approaches to autonomy tend to be discussed more than any others: 1) autonomous choices; 2) autonomy as a legal capacity; 3) autonomy as a capacity conceived procedurally; 4) autonomy as a capacity conceived substantively. ${ }^{27}$

Bearing in mind that autonomy considerations tend to focus on medical situations in which decisions need to be made, it is not surprising that the principle of respect for autonomy is most often associated with the idea that physicians should respect patients' autonomous choices. The principle of respect for autonomous choices is a key aspect of Tom L. Beauchamp and James F. Childress' account of autonomy. ${ }^{28}$ In the sense that the decision made by a patient is the outcome of an autonomous choice, it should be accorded respect not because the patient is an autonomous agent but because the choice is autonomous. In other words, autonomy is a property of a choice as opposed to a capacity of the patient. According to Beauchamp and Childress' proceduralist conception of autonomy, a patient's choices are autonomous when they fulfil certain criteria, notably, when the choices are made intentionally, free from controlling influences and with adequate understanding (whereby inadequate understanding can result from 'illness, irrationality and immaturity'). ${ }^{29}$ 
The remaining approaches consider autonomy to be a capacity of individuals as opposed to a property of their decisions. There are two ways in which 'capacity' can be interpreted in the context of patient decision making. Firstly, as a 'legal capacity', which establishes a patient's rightful position to reach a decision on the basis of their sovereignty. Secondly, as a capacity for 'self-governance', that is, a capacity to rule oneself, whereby the conditions for self-government are often defined procedurally or substantively.

In terms of a 'legal capacity', Tom Walker argues that there is a domain within which 'the individual rules him or herself, and hence this is the sphere of their autonomy'. ${ }^{30}$ Both Walker and David Archard acknowledge that this sovereignty account of autonomy is a juristic approach supported by the tort of battery in the case of English Law. ${ }^{31}$ It reflects a patient's liberty; specifically, their right to refuse or permit a particular treatment being offered. ${ }^{32}$ The point is that violations of a patient's sovereignty should not be confused with interferences with the capacity for a patient to make decisions for themselves. ${ }^{33}$ As Bruce Jennings and James Griffin have observed, there is a distinction between a liberty-based approach to autonomy and the capacity for self-governance. ${ }^{34}$ The sovereignty approach to autonomy concerns an individual's right to permit or refuse treatment. If violations of a patient's sovereignty are wrong, then they are so in the sense that they are considered to be 'trespass[es] upon the body of that person' without consent as opposed to specific interferences that affect a patient's capacity to make decisions for themselves. ${ }^{35}$ However, this sovereignty-based legal capacity only extends to those that fulfil the demands of 'mental capacity'. Specifically, juvenility, mental impairment and factual ignorance all may bar a person from having privileged liberty at law. ${ }^{36}$

According to John Christman, traditional accounts that interpret 'capacity' in the sense of selfgovernance have been intimately bound up with the notion of individuality. ${ }^{37}$ As John Harris claims, 'it is only by the exercise of autonomy [as the capacity to make decisions for oneself] that our lives become in any sense our own'. ${ }^{38}$ Certain accounts suggest that an autonomous agent must meet certain procedural criteria. The conditions that are most often invoked are those that pertain to the capacity for competency. Different accounts stipulate different conditions. However, in medical decision-making contexts, it is generally accepted that a competent person must have the capacity to understand information, reflect on and revise beliefs and make a decision in the light of information. ${ }^{39}$ Of course, competence is a matter of degree and can vary depending on the situation; the same person can be competent to make one decision but not another. The second family of conditions are authenticity conditions, which, as Christman observes, are employed to ensure procedural independence and to stress the self-reflective, self-endorsing nature of personal autonomy. ${ }^{40}$ The point is that a patient's values, desires and motives can be more or less autonomous depending on whether the processes or volitional structures by which they come to be developed are truly their own. Values, desires and motives that have been endorsed as a result of systematic self-deception, manipulation or coercion are not usually considered to be authentic. However, as Paul Benson observes, procedural theories come in a variety of forms; some require actual reflective endorsement; others demand counterfactual endorsement whilst others still require the absence of feelings of alienation as opposed to any form of 'positive endorsement'. ${ }^{41}$ At other times, autonomy is located in decisions, in different aspects of the self or in the structural relations between various values, desires and motives.

Another feature of procedural theories is that they do not stipulate what the content of one's values, desires or motives should or should not be. Such theories are often considered to be 'content neutral'. If autonomy required an individual to follow certain norms and not others on the basis of particular values, desires or motives, then it would need to be considered substantively. The substantive approach has been adopted either to bridge the gap between personal 
autonomy and moral autonomy or as means to ensure that autonomy is not wrongly attributed to individuals who internalise oppressive values. desires and motives as a result of oppressive social conditions and personal circumstances. ${ }^{42}$

When it comes to a conception of autonomy as a capacity for self-governance, Christman argues that both procedural and substantive approaches that focus on the individual self of selfgovernment have failed to rigorously account for the wavs in which interpersonal relationships and social structures contribute to personal autonomy. ${ }^{43}$ Even though we might still define autonomy 'as an individual undertaking, as a set of capacities, which a person, apart from others, might exercise', 44 the values, desires and motives on which exercising one's individual autonomy are based and the commitments and decisions that result from exercising one's autonomy tend, nevertheless, to be regarded as dependent upon and (to varying degrees) derived from social structures and one's interpersonal relationships. In other words, even if Christman considers the exercise of autonomy to be an individual undertaking, there is still an aspect of our capacity for autonomy that is relational (in a derivative sense). This point has been made by Catriona Mackenzie, Natalie Stoljar and Paul Benson. ${ }^{45}$ Not only do they claim that procedural conceptions of autonomy draw attention to the fact that an individual's capacity for autonomy can be nourished or undermined by interpersonal relationships, they argue that individualised procedural and substantive theories actually appear to be responsive to relational dimensions of autonomous agency (if only in a derivative and contingent sense).

In medical ethics and bioethics as well, overly individualised conceptions of the procedurallyindependent/substantively-independent agent have been called into question on the basis that they do not carefully account for the ways in which conditions for personal autonomy and exercises of autonomy depend upon interpersonal relationships. ${ }^{46}$ It has been claimed that overly individualised conceptions of autonomy in medical ethics reduce the patient-physician relationship to that of client and technician. ${ }^{47}$ Such a relationship is considered to be another form of paternalism because it promotes preference- and value-neutrality on the part of the physician and limits their role to a provider of information. ${ }^{48}$ In such circumstances, patients can feel neglected and abandoned. ${ }^{49}$ Consequently, it is claimed that the purpose of SDM is to not only inform patients about viable options and encourage patients to achieve informed preferences, but support a capacity of autonomy that depends upon interpersonal relationships. 50

Although autonomy as an individualised capacity is often contrasted with autonomy as a relational capacity, that is, with relational autonomy, this article does not consider the former independently from the latter. ${ }^{51}$ As Mackenzie and Stoljar argue, relational autonomy does not refer to a single account but is rather an 'umbrella term', 52 which refers to all views of autonomy 'premised on a socially embedded conception of agency'. ${ }^{3}$ The autonomy literature in contemporary philosophy shows just how difficult it is to make hard-and-fast distinctions between different approaches to autonomy as a capacity. ${ }^{54}$ Instead, the capacity for autonomy considered here might, for the purposes of this article, be better viewed as a spectrum of theories ranging from more individualised approaches, according to which interpersonal relationships and social conditions contribute to an individual's ability to exercise their autonomy and/or satisfy the conditions of autonomy, ${ }^{55}$ to 'stronger', value-saturated accounts whereby interpersonal relationships and social structures conceptually constitute an individual's autonomy. ${ }^{56}$ Christman, for example, claims that a theory of autonomy is 'uniquely' relational if it posits particular normative social conditions as 'conceptually necessary requirements of autonomy'. ${ }^{7}$ Whereas Christman accepts that interpersonal relationships and social conditions contribute to an agent's psychological states and are thereby part of the 'background requirements' for the exercise and 
development of autonomy, ${ }^{u}$ a 'thoroughly relational view of autonomy' presumes the metaphysical claim that autonomv is a property of the relations that comprise social conditions in which an agent is embedded. ${ }^{59}$ If that is the case, then, according to Christman, being autonomous means being embedded in the right kinds of social conditions with the right kinds of interpersonal relationships. As a result, 'stronger' substantive theories of autonomy located in the 'constitutive' end of the relational spectrum demand that, in order to count as autonomous, an individual not only must commit to certain norms on the basis of particular values, desires or motives, they must be treated in socio-relational contexts in a certain normatively acceptable way.

There are, of course, 'weaker' substantive approaches to autonomy that can be located somewhere between content-neutral, procedural conceptions and stronger substantive theories. According to Benson, such approaches incorporate normative content. However, that content does not directly constrain either the types of commitments and decisions that agents autonomously make or the values, desires and motives on which such commitments and decisions are based. ${ }^{60}$ Furthermore, they contain procedural elements in the form of competency conditions, such as the normative competence to reflect on information, to recognise and respond appropriately to norms that apply to certain commitments, to answer for commitments and decisions in the space of giving and asking for reasons and to adopt particular recognitive relationships to oneself such as self-trust and self-respect. ${ }^{61}$

As far as clinical decision making is concerned, and insofar as the self-governing agent is conceived relationally, accounting for autonomy as capacity for self-governance extends the traditional notion of respect for autonomy beyond the immediate clinical decision to the broader context of relations that shape the decision. Not only does the capacity approach to autonomy highlight the social, mutually-dependent nature of human agency, it suggests that, as Mackenzie observes, an adequate theory of autonomy must be based on recognition of the ways in which an individual's values, desires, motives, commitments and decisions depend upon interpersonal relationships and social environments. ${ }^{62}$

\section{Respecting Decisions and the Conditions of Autonomy}

Proponents of SDM disagree as to whether the culminating decision should belong to the patient or the physician or whether it should be (in some sense) shared. However, if SDM is to respect patient autonomy, then there are autonomy-based obligations requiring patients to make the final decision. Although some conceptions of autonomy, namely, autonomous choices and autonomy as a legal capacity, do not invoke the typical conditions of SDM, it is important to consider these approaches. If a patient satisfies the conditions for autonomy required by these particular accounts, yet the physician overrules that decision in order to fulfil the requirements of SDM, then the latter would have failed to respect the patient's autonomy, something that SDM is meant to protect against.

When it comes to the first approach, physicians should respect a patient's decision if it is an autonomous decision. However, if a patient does not make a choice or if their choice is not autonomous, then a physician would not be violating the principle of respect for autonomy were they to make the decision for them (though they may violate typical standards of patient consent). The point is that the requirement to respect autonomous choices does not impose an obligation on a physician to obtain an autonomous decision. Respect for autonomous choices means that so long as a patient's choice is intentional, based on adequate understanding and made without controlling influences, then that choice should be respected. 
Autonomy as a sovereignty-based legal capacity demands that the patient has the right to make the final decision. If there is a domain over which the patient is sovereign, then trespasses upon a patient's body without explicit, voluntary consent would disrespect their autonomy. The patient's rightful authority to permit or refuse treatment cannot, according to the principle of legal capacity, be usurped by any other. Furthermore, the patient's decision must be respected. ${ }^{63}$ As John Coggon observes, these requirements are consistent with settled legal principle; law 'protects patients from interference: lawful reason is required before it is permissible to breach a person's bodily integrity', whereby such reasons include consent or a relevant decision of the court. ${ }^{64}$ The requirement to respect a patient's sovereignty operates in law on the presumption that, specifically, adult patients (those over the age of 16 in the UK) have mental capacity. If we follow, for example, sections 2(1) and 3(1) of the UK's Mental Capacity Act 2005 ('MCA'), then an adult patient must not have an impairment of, or a disturbance in the functioning of, the mind or brain that affects their ability to make a decision for themselves.

Turning to the conception of autonomy as a capacity for self-governance, one might claim that if a patient has such a capacity, then respect for autonomy requires physicians to allow patients to make decisions. However, as Coggon and Miola observe with regards to English medical law, 'there is a concern not just for the capacity for reason, but also for the effective use of it'. ${ }^{65}$ For example, common law has developed the category of the 'vulnerable adult', who meets the MCA's test for mental capacitv but is denied decision-making power in order that 'more rational' decisions may be effected. ${ }^{66}$ What this shows is that when the statutory test is read in conjunction with established medical jurisprudence, there is some level of obligation to ensure that the patient has exercised their general abilities for decision making appropriately. The point is that if 'autonomy exists and can be tested in people's exercise of reason' 67 then not allowing a patient to make a decision when they meet certain competency and authenticity conditions would be to violate the principle of respect for autonomy. ${ }^{68}$ In effect, the physician would have failed to recognise the patient as having the normative authority to competently and authentically make decisions informed by their own values, desires and motives. ${ }^{69}$ Of course, a patient does not have to choose wisely. If a physician overrules a decision made by a patient who, according to the typical accounts of competency in medical ethics, understood the information provided, reflected on that information and made a decision in the light of it but whose choice, ultimately, was not in their best interests, then that physician has failed to respect the patient's autonomy. Furthermore, recognition of the individual's normative authority entails that the individual cannot be manipulated or coerced into making a particular decision. ${ }^{70}$ To do otherwise would be to violate conditions of authenticity that are deemed to be necessary to guarantee procedural independence in the exercise of autonomy. However, if a patient has been coerced or has not understood the information provided or has made a decision that does not cohere with the information, there would be no reason to think that he has normative authority over his decision. There would be no failure to recognise the patient as having normative authority to exercise their autonomy if the patient lacks normative authority. As a result, denying a patient the opportunity to make a decision in such circumstances would not violate the principle of respect for autonomy (though, as we shall see in the next section, it may violate the principle of respect for the patient's sovereignty).

What this recognitive relationship demonstrates is that the exercise of one's normative authority to make decisions has a fundamentally social dimension. ${ }^{71}$ Arguably, the most comprehensive explanation of this idea has been presented by Robert Brandom, and it is helpful to understanding the decision-making implications of those approaches to autonomy where interpersonal relations and social conditions either conceptually constitute autonomy or contribute to it. 72 
Brandom adopts the Kantian idea that a judgment is a practical commitment over which we have a degree of authority and for which we are responsible. He argues that commitment, authority and responsibility (entwined as they are in judgments) are 'statuses'. They are both attitudedependent (in the sense that they result from the practical attitudes of the individual making the judgment) and normative (in the sense that they can be assessed as appropriate or inappropriate, correct or incorrect). According to Brandom, I cannot, by myself, determine whether a certain commitment is appropriate or correct. What counts as appropriate is constrained by the normative standards built into our shared practices. It is not enough that I merely exercise my normative authority and acknowledge that others have a degree of authority over what I am committed to; others must hold me responsible and exercise their normative authority over what I am committed to, responsible for and authoritative about. From a clinical perspective, decision making involves patients and physicians making claims in the eyes of each other (and, as we shall see, others) in the socially-situated aame of commitment making, a game that is made explicit in the giving and asking for reasons. ${ }^{73}$ On Brandom's account, exercising one's autonomy is, therefore, a process that depends upon the mutual recognition of normative statuses between decision makers and their discursive partners. ${ }^{74}$ That the exercise of one's autonomy should depend so much on the way one is perceived and treated by others may seem counterintuitive. However, there is little that is controversial in the idea that one's commitments have a normative force that goes beyond one's specific practical attitudes. Similarly, there is little that is controversial in the idea that one's decisions make one accountable to others. On that basis, we should not be surprised by the fact that one's normative authority to exercise one's autonomy depends upon, and can only be sustained by, relations of intersubjective recognition of normative statuses. ${ }^{75}$

If our commitments depend upon a structure and process of recognition, and if exercising one's autonomy is an expression of our commitments, then approaches to autonomy emerge that are, as we have seen, dependent upon socio-relational situations. ${ }^{76}$ It follows that without the manifestation of the recognitive relationship between a patient and physician, a patient is unable to engage genuinely in the normative game of giving and asking for reasons and, on that basis, a patient cannot genuinely exercise their normative authority in making decisions. On the basis that a recognitive relationship contributes to the personal autonomy of the patient, such a relationship cannot be coerced or manipulated - it must be genuinely mutual. Furthermore, the physician, the patient and all other parties involved in the clinical decision cannot be indifferent to potential power differentials that could, if left unchecked, distort relationships of intersubjective recognition, lead to a failure of recognition, undermine the genuineness of decisions and impair personal autonomy. ${ }^{77}$ As Axel Honneth argues, deviations from the mutual recognitive relationship are indicative of 'forms of recognition that must be regarded as being false or unjustified because they do not have the function of promoting personal autonomy, but rather of engendering attitudes that conform to practices of domination'. ${ }^{8}$ Indeed, as we shall see, for substantivists, on the basis that recognitive relationships constitute the autonomy of patients, potential imbalances in power can and should be addressed in order to promote patient autonomy. For more procedural approaches, however, respect for autonomy that is grounded in the satisfaction of procedural criteria allows the patient to be autonomous even if they adopt a dependent role in the patient-doctor relationship. In other words, so long as they would not reject those conditions having reflected appropriately about their role in the relationship free from various distorting influences, a patient who meets the procedural criteria for autonomy should be able to allow the physician to intervene paternalistically when it comes to a particular treatment decision. ${ }^{79}$ That said, even procedural approaches, insofar as they acknowledge that recognitive relationships contribute to personal autonomy, need to consider the role that power can play in 
clinical decisions, especially when physicians are engaged in decision-making contexts involving patients who do not have the normative authority to properly exercise their autonomy.

As we have seen in the previous section, proceduralists still affirm the model of the reflective, self-endorsing individual. After all, the exercise of one's autonomy depends, in part, on the recognition of one's normative authority to make commitments and articulate decisions that express those commitments in light of the choices with which one is presented, one's values, desires and motives and one's reflection on the information provided by discursive partners. However, due to the fact the explicit exercise of one's autonomy depends upon, and can only be sustained by, relations of intersubjective recognition, proceduralists are required to adapt traditional accounts of competency and authenticity conditions. ${ }^{80}$ To characterise competency exclusively in terms of individual understanding, reflection and decision is insufficient. Furthermore, an adequate account of authenticity must acknowledge that processes of understanding, reflection and decision are shaped by intersubjective relationships. The fact that an individual cannot, by themselves, determine whether a certain commitment is appropriate means that the individual is answerable to others. In a clinical context, when a patient makes a decision in the eyes of the physician, their commitments demand reasons. Consequently, an additional requirement for the proper exercise of a patient's autonomy is the giving of reasons for any decisions that are made. Furthermore, owing to the fact that the recognition of normative statuses is a mutual process, a patient is required not only to recognise the commitments made, and the reasons given, by their physician, but, as Christman observes, to reflect on, and respond appropriately to, those reasons. ${ }^{81}$ However, the patient is not just answerable and accountable to the physician. In medical contexts, certain treatments will require the recognitive relationship to be expanded to include other social agents, typically, the patient's immediate family. After all, if an elderly patient decides that they want to remain in their own home to be cared for by their three sons and visiting care staff, then, as these individuals are being subjected to certain normative expectations, a patient will be required to recognise and respond appropriately to their commitments and reasons. Just as a patient cannot be forced, coerced or manipulated to take responsibility for the needs of others without being allowed to exercise their autonomy in the space of giving and asking for reasons, those that might be expected to fulfil certain obligations in the care of the patient as a result of the latter's decision must also be accorded the opportunity to exercise their autonomy. Otherwise, the patient's decision, even if recognised and accepted by a physician, would still result in a failure of respect for autonomy.

As we previously observed, 'stronger' substantive theories of autonomy located on the 'constitutive' end of the relational spectrum demand that a physician recognise and respect a patient's decisions if and only if the latter is treated in socio-relational contexts in a certain normatively acceptable way and commits to some kind of externally-defined value structure. ${ }^{82}$ According to Christman, such an approach implies that patients who fail to meet these conditions do not have the normative authority to make decisions for themselves. ${ }^{83}$ On that basis, one could claim that if a patient does not meet these criteria for the exercise of their autonomy, there is no obligation to allow the patient to make a decision. This conclusion, however, is not affirmed by the majority of strong substantivists for the reasons that will be articulated in the next section.

Stronger substantive approaches also come into conflict with more procedural approaches. On a proceduralist view of judgment in socio-relational contexts, exercising one's normative authority is dependent upon, and sustained by, intersubjective relations of recognition such that one is accountable to others in the space of giving and asking for reasons. However, according to Mackenzie, the amalgam of this recognitive framework of commitment-making and reason-giving and more traditional conditions of procedural independence, reflection and self-endorsement is still not sufficient to account for autonomy. ${ }^{84}$ What is needed to exercise one's autonomy is one's 
commitment to particular intrinsic values. Specifically, one is required to endorse certain nonauthoritarian values that are considered to be valid independent of an individual's authentic commitment to them.

\section{Obligations to Respect Autonomy and the Requirements of Shared Decision Making}

This section looks at how these different conceptions of autonomy, together with their associated obligations, relate to the standard account of SDM considered in this article. To recap, the general consensus is that physicians should offer options, describe their probable benefits and potential harms, account for a patient's values, present their recommendations and allow the patient to communicate preferences.

If respect for autonomy is conceived as respect for autonomous choices, then it is clear that a physician is not obligated to meet these SDM conditions in order to respect a patient's autonomy. As we have seen, respect for autonomous choices demands that physicians respect the actual autonomous decisions that are made. It does not generate a requirement to obtain an autonomous decision nor does it (on its own) generate any obligations when no autonomous decision is forthcoming. It follows that, on the one hand, if a patient's autonomous choice is overruled in order to achieve mutual agreement or if proponents of SDM demand that the culminating decision is the physician's responsibility, then, rather than respecting autonomy, SDM threatens it. On the other hand, if we believe that SDM requires the patient to decide what treatment they will or will not receive and that they be allowed to make their decision before a physician decides, then such a normative position cannot be fully captured by the principle of respect for autonomous choices. ${ }^{85}$ Furthermore, physicians are not obliged to offer options, provide information on those options, take into account a patient's values or obtain informed preferences in order to respect autonomous choices. Bearing in mind, however, that, according to Beauchamp and Childress, a necessary condition for autonomous choices includes adequate understanding on the part of the patient, it seems that some information needs to be provided in order for adequate understanding to be a possibility. Without it, there is nothing to be understood and, therefore, no possibility for autonomous decision making.

Respect for autonomous decisions requires a physician to provide enough information for a patient to make a choice in a way that does not coerce or manipulate them. Although respect for autonomous decisions does not in itself generate a requirement to obtain informed consent, ${ }^{86}$ it cannot be considered independently of patient consent in the context of real clinical decisions. The point is that even if a patient does not make an autonomous choice with regards to treatment options, to treat them without their consent is inconsistent with their rightful authority to permit or refuse a treatment required by the principal of respect for autonomy as sovereignty. Consequently, the information that needs to be disclosed is, as Walker observes, broadly in line with what is required by English law to avoid the tort of battery; specifically, the supplied or withheld information should not manipulate the patient or undermine the voluntariness of their decision and the patient must know what the physician is going to do to them if they consent to one of the treatment options. ${ }^{87}$ Although this obligation prevents a physician from deciding upon a patient's treatment before they supply them with such information, respect for autonomous choices in itself does not require the physician to obtain an autonomous decision about which treatment they will or will not receive. In addition, respect for autonomous choices in itself does not require the physician to meet those SDM conditions that go beyond providing the basic, relevant information needed to avoid the tort of battery. What this shows is that where respect for autonomous choices and legal capacity are exclusively concerned, as opposed to, say, the patient's best interests or epistemic considerations, the conditions for autonomy do not require a physician to describe the probable benefits and potential harms of the proposed treatment(s) nor 
do they require a physician to take into account a patient's values in accordance with the typical conditions of SDM. Even though one might think that it is in the patient's best interests to have the physician present them with treatment options and recommendations that take into account their values, if a physician's consideration of a patient's values leads to a patient's autonomous decision being overruled, then it would be difficult to see how SDM fulfils the ethical imperative of respecting patient autonomy.

As detailed in the previous section, one's commitments, and the claims that express those commitments, are subject to normative constraints that are built into, and constructed from, social practices such that the exercises of one's autonomy depend upon socio-relational conditions of intersubjective recognition. As a result, according to more procedural approaches to autonomy as a property of persons, a physician should, when certain competency and authenticity conditions are met, recognise the patient as having the normative authority to make decisions based on their own values, desires and motives. Otherwise, a failure of recognition would impair the patient's autonomy. This does not mean that a physician is obligated to provide a patient with whatever treatment they demand. A physician need only allow a patient to make a decision about the viable options that the local health care system makes available to individuals with the pertinent condition. ${ }^{88}$ However, if a generally competent patient is unable to competently and authentically exercise their normative authority regarding a specific choice, respect for autonomy does not require a physician to withhold from making a decision about what treatment the patient will or will not receive (so long as they, subsequently, obtain the patient's consent to that treatment). On that basis, there does not, at this stage, appear to be a conflict between what is required by the principle of respect for autonomy as self-governance and the conditions detailed in standard accounts of SDM.

As is the case with autonomous choices, a physician is also obligated to provide basic and relevant information regarding the viable options in order to support the conditions necessary for competency. ${ }^{89}$ Again, bearing in mind that respect for autonomy as a capacity cannot be considered independently of patient's sovereignty-based legal capacity to permit or refuse a treatment, the physician should ensure that the supplied or withheld information does not undermine the voluntariness of the patient's decision and they should ensure that the patient is aware of what the proposed treatments involve in relation to bodily trespass. However, this does not mean that a physician is obligated to describe the probable benefits and potential harms of the treatment options in order to avoid the tort of battery. For example, in a case where a physician is aware that a patient does not want chemotherapy, having experienced side effects of nausea, vomiting, constipation and chronic fatigue, SDM would require the physician to provide information about the side effects of viable alternative treatments even if the patient does not request it. The point is, however, that if SDM requires the physician to disclose this sort of information in light of a patient's prior experiences, then the reasons for it cannot be captured by the principle of respect for autonomy as capacity. For example, Coggon and Miola demonstrate that when it comes to case law, reasons for the disclosure of material risks and benefits have been dealt with by the law of negligence rather than the tort of battery. ${ }^{90}$

As Coggon and Miola also observe, the disclosure of treatment risks can undermine a patient's autonomy. If a generally competent patient states that they wish to make a decision based on values, desires and motives unrelated to material risks and benefits or if they request that such information be withheld, then a physician would not be obligated to provide it even if the absence of information pertaining to risks and benefits contributes to an uninformed decision. ${ }^{91}$ Where respect for autonomy as a capacity is exclusively concerned, there is no autonomy-based requirement to provide more than the information needed for the patient to exercise their normative authority in making a choice unless they ask for such information or the reasons for 
their preferences indicate that they value such information. If a physician insists on providing information pertaining to risks and benefits, then the physician could be deemed to be interfering with their decision by, in effect, deciding for the patient which values, motives and desires should inform their decision. This could undermine the conditions of authenticity that more procedural approaches consider necessary for the exercise of autonomy. Even if proponents of SDM claim that the model of offering and allowing patient choice leads to patients 'feeling abandoned rather than autonomous', ${ }^{92}$ the point is that when autonomy is conceived as a property of persons, a physician is under no autonomy-based obligation to fulfil the requirements of SDM that go beyond providing the information needed to avoid the tort of battery (unless a generally competent patient requests specific or additional information or the reasons for their preferences indicate that they value such information) and allowing the patient to exercise their normative authority in making decisions. Indeed, if a physician played a more prominent role in the decision-making process in order to fulfil the conditions of SDM, then they would undermine, rather than respect, the autonomy of competent patients. What this demonstrates is that when it comes to respect for autonomy, clinical decisions are sensitive to power differentials. ${ }^{93}$ The provision or withholding of pertinent information, for example, can affect the recognitive relationships between physician and patient differently in different circumstances. In one situation, the withholding or provision of certain information can help a patient satisfy the conditions for autonomy; in another, the same information can impair a patient's autonomy. By not considering the ways in which recognitive relationships, in part, contribute to, develop and impair personal autonomy, standard accounts of SDM have failed to adequately demonstrate that this particular approach to clinical decision making does, in fact, respect patient autonomy.

When autonomy is conceived as a capacity in a more procedural sense or a 'weaker' substantive sense, there are, as we observed in relation to Brandom's framework, specific obligations that have not received general acknowledgment from proponents of SDM. For example, on the basis that one's commitments and the recognition of the appropriateness of those commitments are made explicit in the space of reasons, a patient is required to provide appropriate reasons for their choice and to recognise, reflect on, assess the appropriateness of, and respond appropriately to the commitments made, and reasons given, by those who can be reasonably expected to be normatively affected by the decision. Consequently, as well as providing a patient with viable options and the basic, relevant information needed to avoid the tort of battery, a physician is obligated to respond to requests for specific information from those who are likely to be normatively affected by the patient's decision. Furthermore, respect for the patient's autonomy generates a requirement for the physician to recognise, reflect on, assess the appropriateness of, and respond appropriately to, the patient's commitments and reasons. This does not mean that a physician has to agree with the patient. Rather, the physician considers whether the patient's commitments and reasons are appropriate according to the normative standards built into health practices. For example, if a pregnant woman decides upon non-invasive prenatal testing ('NIPT') yet provides reasons that support the conclusion that she is not, in fact, comfortable with receiving any form of screening or diagnostic testing, then there is no autonomy-based reason for the physician to respect the decision. Similarly, if, say, a father of a young child with severe developmental delay does not recognise, or respond appropriately to the mother's appropriate commitments and reasons, yet decides that the child should be cared for by specialist health care professionals away from the family home rather than receive a therapy that would stunt the child's growth, then respect for autonomy does not require the physician to comply with their choice. In both examples, the decision makers have not fulfilled the necessary normative competency conditions: in the first example, the pregnant woman has not provided appropriate reasons for her choice; in the second, the father has not respected the autonomy of the child's mother. Consequently, where respect for autonomy is concerned, an appropriate 
response in both cases would be for the physician to overrule the decision (so long as the physician's choice of treatment is appropriate and suitable consent is given).

In order to support the conditions for normative competency, the physician will require information. If the physician has the capacity to decide for themselves which values, desires and motives are to inform their decision, then, in order to respect the physician's autonomy, the patient is obligated to provide any information that the physician deems to be necessary to inform their choice. The physician may wish to make a decision based on the patient's values and preferences in accordance with the demands of SDM. However, the physician might wish to base their decision on the appropriate commitments made, and the reasons given, by the patient's family members. Consider, for example, a case of an adult patient with amyotrophic lateral sclerosis ('ALS'), who is able to communicate verbally to a certain degree but who does not have mental capacity and has lost the ability to walk and move their body below the neck. It is clear that the immediate family would prefer to have the patient cared for at home. The physician's initial response might be to recommend and support the installation of lifting aids in the home. However, the patient's immediate family inform the physician that the physical contact of being lifted seems to be what gives the patient the most pleasure in life. It seems reasonable to suggest that such information is normatively pertinent to the physician's decision. The point is that so long as the physician's commitments and reasons are appropriate according to typical normative standards and so long as the patient has not fulfilled the necessary conditions for autonomy, respect for autonomy as a capacity does not generate a requirement for the physician to base their decision on the values and preferences articulated by the patient. It follows that even if the physician bases their decision on the patient's values and preferences, respect for a patient's autonomy does not require the patient to describe these details in every decisionmaking context. Such information is only required if the physician asks for it when the patient has not met the necessary conditions for competency and authenticity. If a patient insisted that the physician base their decision on the former's values and preferences, then this could be perceived as an example of coercion or manipulation, which, if true, would fail to respect the physician's normative authority to exercise their autonomy.

In overruling a decision when a patient has not met the conditions for a more procedural or 'weak' substantive conception of autonomy, a physician, on the basis that they are answerable to the patient in the space of giving and asking for reasons, is obligated to provide appropriate reasons for their decision about which of the viable treatments the patient should receive. As we have seen, the physician is also required to recognise, and respond appropriately to, the commitments made, and the reasons given, by those that can be reasonably expected to be normatively bound by the decision. Again, however, if the physician has fulfilled the necessary conditions for autonomy, which includes making appropriate commitments, giving appropriate reasons for their choice and respecting the autonomy of, for example, the patient's family members, then there is no autonomy-based reason for the physician to adapt their commitments and reasons in the light of the patient's response to their overruling. If a generally competent patient is unable to properly exercise their normative authority in making a specific decision about viable treatment options, respect for autonomy does not require a physician to wait for the patient to fulfil those conditions or withhold from making their own choice. However, as we have already observed, the fact that, in real clinical contexts, respect for autonomy cannot be considered independently of patient's sovereignty, the physician is required to allow the patient to permit or refuse a specific treatment on the grounds of bodily trespass and the law of battery.

This (far too) brief discussion of physician/patient obligations in decision-making contexts involving normatively non-competent patients indicates that standard accounts of SDM have operated on the general assumption that patients are able to fulfil the necessary conditions to 
exercise their autonomy and thereby to have their autonomy respected. Furthermore, this discussion demonstrates that such accounts have considered neither the vulnerability of patients to interpersonal relationships nor the ways in which different kinds of recognitive relationships can, at different times, contribute to, develop or impair a patient's autonomy in clinical contexts.

From a stronger substantivist point of view, a physician should recognise and respect a patient's decisions if and only if the latter is treated in socio-relational contexts in a certain normatively acceptable way and commits to some kind of externally-defined value structure. This stronger substantive approach located in the 'constitutive' end of the relational spectrum implies that patients who fail to meet these conditions do not have the normative authority to make decisions for themselves.

Mackenzie argues that there might be good reason to doubt a patient's normative authority because of, for example, illness, internalised oppression, stigmatisation or inappropriate normative expectations resulting from previous encounters with overly paternalistic or demeaning health care practices. The key point is that interpersonal relationships can affect one's ability to recognise one's normative authority, one's recognition of which values, desires and motives inform one's commitments and one's ability to recognise one's commitments as meaningful, worthwhile and valuable. ${ }^{94}$ For example, as a result of being in an abusive, subservient relationship, a patient may have no confidence in the decisions they make or they may not perceive themselves as having the authority to make commitments in the first place. Alternatively, a patient may make (what both their physician and family deem to be) an appropriate decision for appropriate reasons. However, unbeknown to their physician and family members, the patient has consistently experienced strong paternalistic health care interventions. As a result, they have based their decision on those values that previous health care practitioners have imposed on them. In circumstances like this, Mackenzie claims that a patient's autonomy is compromised such that respecting their choice would not, in fact, be consistent with respecting their autonomy. ${ }^{95}$

For Mackenzie, 'respect for autonomy involves an obligation to promote autonomy'. ${ }^{96}$ As already observed, certain proponents are explicit in claiming that a key requirement of SDM is to promote patient autonomy. ${ }^{97}$ Of the four conceptions of autonomy that have been considered, 'stronger' substantive approaches are the only ones according to which respect for autonomy entails an obligation to promote a patient's autonomy. In other words, if proponents consider the promotion of a patient's capacity for autonomy to be a necessary condition of SDM, then the only conceptions of autonomy that are applicable to SDM contexts are more value-saturated, relationally-constitutive conceptions of autonomy. However, if that is the case, then there appears to be a conflict between standard accounts of the requirements of SDM and the obligations substantivists require to respect patient autonomy.

Firstly, whereas SDM is considered to be an extension of informed consent, the need to respect autonomy does not in itself generate a requirement to obtain informed consent. As we have seen, respect for autonomy as a capacity for self-governance cannot be considered separately from a patient's sovereignty. Nevertheless, in order to have their sovereignty-based legal capacity respected, a patient need not be 'informed' in the usual sense that requires details of benefits and risks. To reprise, all that is required is for the physician to ensure that the supplied or withheld information does not undermine the voluntariness of the patient's decision and to ensure that the patient is aware of what the proposed treatments involve in relation to bodily trespass. As we have seen, what this means is that the requirement of SDM to disclose purported benefits and potential harms in line with the standard statutory requirements for informed consent cannot 
be captured by the principle of respect for autonomy as sovereignty or as a capacity for selfgovernance.

Secondly, whereas the standards of voluntary, informed consent operate in law on the presumption that adult patients have mental capacity and are thereby able to understand, retain and use the information relevant to the decision-making process, stronger substantive approaches to autonomy seemingly reverse the assumption that patients who are of age have the normative authority to make decisions for themselves. This reversal is encapsulated in Mackenzie's demand that, when it comes to the physician-patient relationship, 'respect for her autonomy involves an obligation not just to understand but to try to shift [the patient's] perspective and to promote her capacities for autonomy'. 98 The fact that Mackenzie argues that this is a requirement of all 'good medical practice' means that there must be some form of assessment of a patient's normative authority at the beginning of the decision-making process. Otherwise, Mackenzie argues, decision-making processes that continued without some form of assessment of normative authority would lack 'care and sensitivity on the part of the treating healthcare professionals' and 'give rise to paternalistic attitudes on the part of medical staff and a sense on the part of patients that they are being coerced'. 99

The reversal of the standard medical decision-making assumption that patients who are of age have the normative authority to make decisions for themselves generates a tension between the requirements of SDM and the obligations that follow from the principle of respect for autonomy conceived in a stronger substantive sense. Firstly, from a substantive point of view, if there is reason to doubt a patient's normative authority, then respect for autonomy in itself does not require the physician to offer viable options and to describe their effectiveness, probable benefits and potential harms. Following Mackenzie's argument, to reasonably doubt a patient's normative authority is to reasonably doubt their ability to recognise the normative authority needed to exercise their autonomy and/or to reasonably doubt their ability to genuinely decide for themselves which values, desires and motives are to inform their decision. Although standard accounts of SDM require a physician to describe the probable benefits and potential harms of viable treatment options in line with the legal requirements of statutory informed consent, there is no corresponding 'strong' substantivist reason for them to do so unless a patient requests such information having sufficiently revised their perspective in order to achieve the necessary selfrecognitive relationship to genuinely exercise their relational autonomy (or, depending on the particular substantive theory, having revised their perspective in order to commit to the appropriate externally-defined value structure that constitutes their autonomy). Furthermore, whereas proponents of SDM claim that a patient should be allowed to reflect on treatment options, risks and benefits, respect for autonomy conceived substantively generates this requirement only when the patient wishes to base their decision on these specific details and when their autonomy is deemed to be uncompromised such that respecting their choice would be consistent with respecting their autonomy. Similarly, respect for autonomy requires a physician to present viable treatment options only when there is no reason to doubt a patient's normative authority to make decisions based on their genuine values, desires and motives. If the clinical decision satisfied all of conditions of SDM on the statutory presumption that patients of age have the normative authority to make decisions for themselves, then, if we follow Mackenzie's account of autonomy, the patient is likely to feel that the physician is just being coercive thereby failing to respect their autonomy. ${ }^{100}$ Finally, standard accounts of SDM demand that patients describe their values and preferences. If it is reasonable to doubt a patient's normative authority, then a physician, as Mackenzie suggests, is required to empathise with the patient and assist them with revising their perspective in order to achieve the necessary self-recognitive relationship. In order to do this, the physician will be required to take into account any pertinent information supplied by the patient. However, on a stronger substantive conception of autonomy, a patient will be 
required to provide details regarding their values and preferences if and only if such information will provide the means necessary for the physician to enable the patient's affective, selfrecognitive relationship. If the provision of such details is likely to further compromise the patient's normative authority, then respect for stronger substantive conceptions of autonomy does not require the patient to divulge this information.

Although these tensions demonstrate that the requirements of SDM are not always consistent with a standard of respect for autonomy when autonomy is conceived in a value-saturated, relationally-constitutive sense, it should also be noted that the normative constraints placed on individuals by substantive conceptions of autonomy have been called into question in contemporary debates concerning the nature of autonomy. ${ }^{101}$ Those critical of stronger substantive conceptions of autonomy have focussed on the normative constraints that can be observed, for example, in the tensions between the norms of SDM and the requirements generated by the principle of respect for autonomy in order to demonstrate the ways in which value-saturated accounts are defective. ${ }^{102}$ As a result, although standard accounts of SDM undermine patient autonomy when the latter is conceived in a strong substantive sense, it is by no means clear that such a conception is the correct one to employ in matters concerning clinical decision making.

\section{Concluding Remarks}

A key part of respecting patient autonomy is respecting the treatment decisions of patients who satisfy certain conditions. As we have seen, whether a patient's decision should be respected in SDM contexts will depend on whether autonomy is conceived as a property of choices or of persons or as sovereignty, whether what is of value is the legal capacity for, or the exercise of, autonomy, and whether the necessary conditions for autonomy are conceived in more of a proceduralist or in more of a substantivist sense. Currently, there is no consensus amongst proponents of SDM about how the culminating decision relates to the principle of respect for autonomy. However, what is clear is that when, as certain proponents claim, the final decision is considered to be either shared or the responsibility of the physician, SDM fails to respect patient autonomy. Furthermore, standard accounts of SDM claim that physicians should offer options, describe their probable benefits and potential harms, take into account a patient's values, present their recommendations and allow the patient to communicate their preferences. However, none of the four principal approaches to autonomy require patients and physicians to satisfy all of these conditions. In the case of autonomous choices, were physicians and patients to fulfil all the conditions required by standard accounts of SDM, then SDM would fail to respect patient autonomy. When we consider autonomy as a capacity in a proceduralist sense, the disclosure of material risks and benefits (without the patient's request for such information) can impair patient autonomy. Furthermore, procedural and 'weak' substantive approaches to autonomy generate specific obligations for both patients and physicians that are not included in standard accounts of SDM. This is a problem because failures to fulfil these obligations will, in principle, undermine patient autonomy. Lastly, if, as certain proponents suggest, SDM is meant to promote patient autonomy, then stronger substantive approaches to autonomy are the only accounts that generate such an obligation. However, as we have seen, the obligations strong substantivists require to promote patient autonomy appear to conflict with the requirements of SDM and medical decision making in general. It is clear that proponents have much more work to do before they can reasonably claim that the SDM model of medical practice is consistent with the principle of respect for patient autonomy.

\section{ACKNOWLEDGMENTS}


This article has been written during a postdoctoral fellowship at the Institute of Ethics, Dublin City University. For its support, and that of Bert Gordijn in particular, I am immensely grateful. A draft of this article was presented at the Political Theory \& Philosophy Seminar series at Queen's University Belfast. I would like to thank Ruth Hewitson, Jonathan Kuyper and Suzanne Whitten for their useful discussions and comments during the seminar. I am also immensely grateful to Søren Holm and Tom Walker for their excellent suggestions in relation to some of the more fundamental arguments in this article. Finally, I wish to gratefully acknowledge the respective contributions of the editor, associate editor, three anonymous reviewers and Kerry Bennett at the Journal of Applied Philosophy.

\section{Notes}

${ }^{1}$ Department of Health, 'Equity and excellence: Liberating the NHS', https://assets.publishing.service.gov.uk/government/uploads/system/uploads/attachment_data/file/213823/c Published July 2010. Accessed 30 October 2018.

${ }^{2}$ Cathy Charles, Amiram Gafni \& Tim Whelan, 'Shared decision making in the medical encounter: What does it mean? (or it takes at least two to tango)', Social Science \& Medicine 44 (1997): 681-92; Dominick Frosch \& Robert Kaplan, 'Shared decision making in clinical medicine: Past research and future directions', American Journal of Preventive Medicine 17,4 (1999): 285-94; Gregory Makoul \& Marla Clayman, 'An integrative model of shared decision making in medical encounters', Patient Education and Counselling 60 (2006): 301-2; Inge van Nistelrooij et al., 'How shared is shared decision-making? A care-ethical view on the role of partner and family', Journal of Medical Ethics 43 (2017): 637-44.

${ }^{3}$ See Makoul and Clayman's systematic review of SDM requirements (op. cit.).

${ }^{4}$ Makoul \& Clayman op. cit. pp. 305-6. The majority, if not all, of these conditions are posited in the SDM accounts of Charles, Gafni \& Whelan op. cit.; Frosch \& Kaplan op. cit.; Carla Keirns \& Susan Goold, 'Patient-centered care and preference-sensitive decision-making', The Journal of the American Medical Association 302 (2009): 1805-6; Glyn Elwyn, Steve Laitner, Angela Coulter et al., 'Implementing shared decision making in the NHS', British Medical Journal 341 (2010): c5146; Amy Leader, Constantine Daskalakis, Clarence Braddock III et al., 'Measuring informed decision making about prostate cancer screening in primary care', Medical Decision Making 32,2 (2012): 327-36; Michael Barry \& Susan Edgman-Levitan, 'Shared decision making - the pinnacle of patient-centered care', The New England Journal of Medicine 366,9 (2012): 780-1; Peter Ubel, Karen Scherr \& Angela Fagerlin, 'Empowerment failure: How shortcomings in physician communication unwittingly undermine patient autonomy', The American Journal of Bioethics 17,11 (2017): 31-9; NHS England, 'About shared decision making', https://www.england.nhs.uk/shared-decision-making/about/.

Accessed 31 October 2018.

${ }^{5}$ Adrian Edwards \& Glyn Elwyn, Shared Decision-Making: Achieving Evidence-Based Patient Choice (Oxford: Oxford University Press, 2009); Elwyn, Laitner, Coulter et al. op. cit.; Glyn Elwyn, Dominick Frosch, Richard Thomson et al., 'Shared decision making: A model for clinical practice', Journal of General Internal Medicine 27,10 (2012): 1361-7; NHS England, 'Shared decision making to meet the ethical imperative', https://www.england.nhs.uk/shared-decision-making/why-is-shared-decisionmaking-important/shared-decision-making-to-meet-the-ethical-imperative/. Accessed 7 November 2018.

${ }^{6}$ Elwyn, Laitner, Coulter et al. op. cit., p. 971.

7Lars Sandman \& Christian Munthe, 'Shared decision-making and patient autonomy', Theoretical Medicine and Bioethics 30 (2009): 289-310; Ubel, Scherr \& Fagerlin op. cit.; van Nistelrooij et al. op. cit.

${ }^{8}$ Glyn Elwyn, Isabelle Scholl, Caroline Tietbohl et al., "“Many miles to go ...": A systematic review of the implementation of patient decision support interventions into routine clinical practice', BMC Medical Informatics and Decision Making 13, Suppl 2 (2013): S14. 
John Wennberg, Tracking Medicine (Oxford: Oxford University Press, 2010).

${ }^{10}$ Ubel, Scherr and Fagerlin op. cit.;

${ }^{11}$ Lisa Dive, 'Autonomy, information, and paternalism in clinical communication', The American Journal of Bioethics 17,11 (2017): 50-52, at p. 51.

${ }^{12} \mathrm{~A}$ principle of respect for autonomy is also occasionally invoked in discussions about confidentiality, fidelity and patient privacy.

${ }^{13}$ Elwyn, Frosch, Thomson et al. op. cit., p. 1361.

${ }^{14}$ Ubel, Scherr \& Fagerlin op. cit. p. 32.

${ }^{15}$ Ubel, Scherr \& Fagerlin op. cit., pp. 36-7.

${ }^{16}$ Dive op cit., p. 51.

${ }^{17}$ Anne Donchin, 'Autonomy, interdependence, and assisted suicide: Respecting boundaries/crossing lines', Bioethics 14,3 (2000): 187-204.

${ }^{18}$ Adrian Edwards and Glyn Elwyn have raised this issue, noting a possible distinction between the process of patient involvement (option presentation, mutual exchange of evidence and the communication of informed preferences) and actual decisional responsibility. They argue that the literature to date has failed to address this distinction in the conceptualisation of SDM. See Adrian Edwards \& Glyn Elwyn, 'Inside the black box of shared decision making: Distinguishing between the process of involvement and who makes the decision', Health Expectations 9,4 (2006): 307-20.

${ }^{19}$ Keirns \& Goold op cit.; Vikki Entwistle, Stacy Carter, Alan Cribb et al., 'Supporting patient autonomy: The importance of clinician-patient relationships', Journal of General Internal Medicine 25,7 (2010): 741-5; Elwyn, Frosch, Thomson et al., op cit.; Ubel, Scherr \& Fagerlin op. cit.; van Nistelrooij et al. op. cit.

${ }^{20}$ David Brody, 'The patient's role in clinical decision-making', Annals of Internal Medicine 93,5 (1980): 718-22; Troyen Brennan, Just Doctoring: Medical Ethics in the Liberal State (Berkeley, CA: University of California Press, 1991); Angela Coulter, 'Partnerships with patients: The pros and cons of shared clinical decision-making', Journal of Health Services Research \& Policy 2 (1997): 112-21; Charles, Gafni \& Whelan op. cit.; Angela Towie \& William Godolphin, 'Framework for teaching and learning informed shared decision making', The British Medical Journal 319 (1999): 766-71; Frosch \& Kaplan op. cit.; W. Wayne Weston, 'Informed and shared decision-making: The crux of patientcentered care', Canadian Medical Association Journal 165,4 (2001): 438-9; Makoul \& Clayman op. cit.; Annette O'Connor, John Wennberg, France Légaré et al., 'Toward the "tipping point": Decision aids and informed patient choice', Health Affairs 26,3 (2007): 716-25; Elwyn, Laitner, Coulter et al. op. cit.

${ }^{21}$ For a discussion of different forms of paternalism in Shared Decision Making, whereby the physician takes responsibility for the final decision, see Sandman \& Munthe op. cit.

${ }^{22}$ Elwyn, Scholl, Tietbohl et al. op. cit.; Amy Lloyd, Natalie Joseph-Williams, Adrian Edwards et al., 'Patchy "coherence": Using normalization process theory to evaluate a multi-faceted shared decision making implementation program (MAGIC)', Implementation Science 8 (2013): 102; Ubel, Scherr \& Fagerlin op. cit.

${ }^{23}$ Elwyn, Laitner, Coulter et al. op. cit.; Barry \& Edgman-Levitan op. cit.

${ }^{24}$ For details of the purported benefits of SDM, see, for example, Elwyn, Laitner, Coulter et al. op. cit.; Barry \& Edgman-Levitan op. cit.; Elwyn, Frosch, Thomson et al. op. cit.; Légaré \& Witteman op. cit.; Joosten, DeFuentes-Merillas, de Weert et al., 'Systematic review of the effects of shared decisionmaking on patient satisfaction, treatment adherence and health status', Psychotherapy and Psychosomatics 77 (2008): 219-26; Dawn Stacey, France Légaré, Krystina Lewis et al., 'Decision aids for people facing health treatment or screening decisions', Cochrane Database of Systematic Reviews 4 (2017): CD001431.

${ }^{25}$ Gerald Dworkin, The Theory and Practice of Autonomy (Cambridge: Cambridge University Press, 1988); Raanan Gillon, 'Ethics needs principles - four can encompass the rest - and respect for autonomy should be "first among equals"', Journal of Medical Ethics 29,5 (2003): 307-12; Tom. L. 
Beauchamp \& James F. Childress, Principles of Biomedical Ethics (Oxford: Oxford University Press, 2013).

${ }^{26}$ For example, John Harris claims that welfare 'create[s] the conditions which not only maximise autonomy but also give autonomy minimum scope for operation'. See John Harris, 'Consent and end of life decisions', Journal of Medical Ethics 29 (2003): 11.

${ }^{27}$ I thank the second anonymous reviewer for raising the point that the notion of autonomous choice is sometimes not viewed as distinct from autonomy as a capacity. As the same reviewer points out, however, my argument is not affected by separating the two. I acknowledge the work of Tom Walker, who has also drawn a distinction between autonomous choices and the capacity for autonomy. See Tom Walker, 'Respecting autonomy without disclosing information', Bioethics 27,7 (2013): 388-94. ${ }^{28}$ Beauchamp \& Childress op. cit.

${ }^{29}$ Beauchamp \& Childress op. cit., pp. 104-5.

${ }^{30}$ Walker op. cit., p. 393. A similar claim is made by Joel Feinberg in his The Moral Limits of the Criminal Law, Vol. 3, Harm to Self (Oxford: Oxford University Press, 1986), pp. 54-5.

${ }^{31}$ Walker op. cit., p. 394; David Archard, 'Informed consent: Autonomy and self-ownership', Journal of Applied Philosophy 25,1 (2008): 19-34, at p. 20.

32John Coggon \& José Miola, 'Autonomy, liberty, and medical decision-making', Cambridge Law Journal 70,3 (2011): 523-547.

${ }^{33}$ Archard op. cit., p. 25.

${ }^{34}$ Bruce Jennings, 'Autonomy' in B. Steinbock (ed.) The Oxford Handbook of Bioethics (Oxford: Oxford University Press, 2007), pp. 72-89; James Griffin, On Human Rights (Oxford: Oxford University Press, 2008).

${ }^{35}$ Archard op. cit., p. 27.

${ }^{36}$ Coggon \& Miola op. cit., p. 543.

37 John Christman, 'Autonomy in moral and political philosophy' in E.N. Zalta (ed.) The Stanford Encyclopedia of Philosophy, Spring (2018):

https://plato.stanford.edu/archives/spr2018/entries/autonomy-moral. Accessed 29 November 2018.

${ }^{38}$ Harris op. cit., p. 11.

${ }^{39}$ Torbjörn Tännsjö, Coercive Care: The Ethics of Choice in Health and Medicine (London and New York: Routledge, 1999); Harris op. cit., p. 12; Beauchamp \& Childress op. cit., p. 114. Manne Sjöstrand et al. 'Paternalism in the name of autonomy', The Journal of Medicine and Philosophy 38,6 (2013): 710-24, at p. 711.

${ }^{40}$ Christman 2018 op. cit.

${ }^{41}$ Paul Benson, 'Feminist intuitions and the normative substance of autonomy' in J.S. Taylor (ed.) Personal Autonomy: New Essays on Personal Autonomy and Its Role in Contemporary Moral Philosophy (Cambridge: Cambridge University Press, 2005), p. 126.

${ }^{42}$ In terms of the former, see, for example, Christine Korsgaard, The Sources of Normativity (New York: Cambridge University Press, 1996). With regards to the latter, see Paul Benson, 'Autonomy and oppressive socialization', Social Theory and Practice 17,3 (1991): 385-408; Marina Oshana, 'Personal autonomy and society', Journal of Social Philosophy 29,1 (1998): 81-102; Natalie Stoljar, 'Autonomy and the feminist intuition' in C. Mackenzie \& N. Stoljar (eds) Relational Autonomy: Feminist Perspectives on Autonomy, Agency and the Social Self (Oxford: Oxford University Press, 2000): pp. 94-111; Marina Oshana, 'How much should we value autonomy?', Social Philosophy and Policy 20,2 (2003): 99-126; Benson 2005 op. cit. pp. 124-42; Catriona Mackenzie, 'Relational autonomy, normative authority and perfectionism', Journal of Social Philosophy 39,4 (2008): 512-33. 43John Christman, 'Relational autonomy, liberal individualism and the social constitution of selves', Philosophical Studies 117,1/2 (2004): 143-64.

${ }^{44}$ Christman 2004 op. cit., pp. 148-9.

${ }^{45}$ Stoljar 2000 op. cit.; Benson 2005 op. cit.; Mackenzie op. cit. 
+u Susan Sherwin, No Longer Patient: Feminist Ethics and Health Care (Philadelphia, PA: Temple University Press, 1992); Carl Schneider, The Practice of Autonomy: Patients, Doctors and Medical Decisions (Oxford: Oxford University Press, 1998); Susan Dodds, 'Choice and control in feminist bioethics' in C. Mackenzie \& N. Stoljar (eds) Relational Autonomy: Feminist Perspectives on Autonomy, Agency and the Social Self (Oxford: Oxford University Press, 2000), pp. 213-35; Onora O'Neill, Autonomy and Trust in Bioethics (Cambridge: Cambridge University Press, 2002); Rebecca Kukla, 'Conscientious autonomy: Displacing decisions in healthcare', Hastings Center Report 35,2 (2005): 34-44; Gordon M. Stirra \& Rita Gill, 'Autonomy in medical ethics after O'Neill', Journal of Medical Ethics 31 (2005): 127-30; Rebecca L. Walker, 'Medical ethics needs a new view of autonomy', The Journal of Medicine and Philosophy 33 (2009): 594-608; van Nistelrooij et al. op. cit.; Ubel, Scherr \& Fagerlin op. cit.

${ }^{47}$ Stirra \& Gill op. cit.

48 James Childress, 'Needed: A more rigorous analysis of models of decision making and a richer account of respect for autonomy', The American Journal of Bioethics 17,11 (2017): 52-4.

${ }^{49}$ Entwistle, Carter, Cribb et al. op. cit.; Elwyn, Frosch, Thomson et al. op. cit.; Childress op. cit. ${ }^{50}$ Entwistle, Carter, Cribb et al. op. cit.; Elwyn, Frosch, Thomson et al. op. cit.

${ }^{51}$ I am grateful to the third anonymous reviewer for their comments that led to the revision of the remainder of this section of the article.

${ }^{52}$ Catriona Mackenzie \& Natalie Stoljar, 'Introduction: Autonomy refigured' in C. Mackenzie \& N. Stoljar (eds) Relational Autonomy: Feminist Perspectives on Autonomy, Agency and the Social Self (Oxford: Oxford University Press, 2000), pp. 3-31.

${ }^{53}$ Mackenzie op. cit., p. 519.

${ }^{54}$ This point has been demonstrated by Diana Meyers. See 'The feminist debate over values in autonomy theory' in A. Veltman \& M. Piper (eds) Autonomy, Oppression, and Gender (Oxford: Oxford University Press, 2014), pp. 114-40;

${ }^{55}$ See, for example, John Christman, The Politics of Persons: Individual Autonomy and Sociohistorical Selves (Cambridge: Cambridge University Press, 2009); Diana Meyers, 'Feminism and women's autonomy: The challenge of female genital cutting', Metaphilosophy 31 (2000): 469-91; Diana Meyers, Gender in the Mirror: Cultural Imagery and Women's Agency (New York: Oxford University Press, 2002). Benson (2005), for example, argues that even though Meyers' competencybased theory is not a 'strong' substantive conception of autonomy, it also does not appear to be purely procedural or content-neutral due to the emphasis she places on the notions of 'self-nurturing', 'self-worth' and 'self-respect' as well the value of 'interpersonal and community solidarity'. Likewise, Christman (2004) argues that any adequate account of authenticity must recognise that not only is a person's practical identity shaped by complex, intersecting social determinants and interpersonal relationships, the process of 'self-reflection' is similarly shaped by these factors. He also suggests that competency conditions in procedural views of autonomy must make room for an agent's capacities for care, intimacy and social interaction.

${ }^{56}$ See, for example, Benson 1991 op. cit.; Oshana 1998 op. cit.; Stoljar 2000 op. cit.; Oshana 2003 op. cit.

${ }^{57}$ Christman 2004 op. cit., p. 147.

${ }^{58}$ Christman 2004 op. cit., p. 158.

${ }^{59}$ Christman 2004 op. cit., p. 156.

${ }^{60}$ Benson 2005 op. cit., p. 125.

${ }^{61}$ See, for example, Benson 2005 op. cit.; Mackenzie op. cit.

${ }^{62}$ Mackenzie op. cit., p. 519.

${ }^{63}$ Walker op. cit., p. 393.

${ }^{64} J o h n$ Coggon, 'Mental capacity law, autonomy, and best interests: An argument for conceptual and practical clarity in the court of protection', Medical Law Review 24,3 (2016): 396-414, at p. 405.

${ }^{65}$ Coggon \& Miola op. cit., p. 528. 
ư Coggon \& Miola op. cit., p. 527.

${ }^{67}$ Coggon \& Miola op. cit., p. 529.

${ }^{68}$ Christman 2004 op. cit.

${ }^{69}$ For a discussion of the link between respect and recognition, see Cillian McBride, Recognition (Cambridge: Polity Press, 2013).

${ }^{70}$ For a discussion of the relationships between normative authority, genuine normative behaviour and coerced normative behaviour, see Jonathan Lewis, 'Hegel and the ethics of Brandom's metaphysics', European Journal of Pragmatism and American Philosophy 10,2 (2018): 1-21.

${ }^{71}$ See, for example, Joel Anderson, 'Autonomy and the authority of personal commitments: From internal coherence to social normativity', Philosophical Explorations 6,2 (2003): 90-108.

${ }^{72}$ See, for example, Robert Brandom, Making it Explicit (Cambridge, MA and London: Harvard University Press, 1994) and Robert Brandom, Reason in Philosophy: Animating Ideas (Cambridge, MA and London: The Belknap Press of Harvard University Press, 2009).

${ }^{73}$ This idea can also be found in Peter Strawson, 'Freedom and responsibility' in his Freedom and Resentment and Other Essays (London: Methuen, 1974), pp. 1-25.

${ }^{74} \mathrm{~A}$ similar point is made in Mackenzie op. cit.

${ }^{75}$ Mackenzie op. cit., p. 524.

${ }^{76}$ Mackenzie op. cit., p. 526.

${ }^{77}$ Axel Honneth argues that this is why intersubjective recognition, in many cases, appears to facilitate attitudes that conform to unjust normative practices. See Axel Honneth 'Recognition as ideology' in B. van den Brink \& D. Owen (eds) Recognition and Power: Axel Honneth and the Tradition of Critical Social Theory (Cambridge, Cambridge University Press, 2009), pp. 323-47. ${ }^{78}$ Honneth op. cit., pp. 324-5.

${ }^{79}$ Such a view is endorsed by Christman 2004 op. cit., pp. 153-5. I'd like to thank the second anonymous reviewer for clarifying the distinction between dependency and subservience.

${ }^{80}$ Christman 2004 op. cit.

${ }^{81}$ Christman 2004 op cit., p. 154.

${ }^{82}$ Christman 2004 op cit., p. 151.

${ }^{83}$ Christman 2004 op. cit.

${ }^{84}$ Mackenzie op. cit.

${ }^{85}$ Walker op. cit.

${ }^{86}$ Walker op. cit., p. 390.

${ }^{87}$ Walker op. cit., p. 394.

${ }^{88}$ Walker op. cit.

${ }^{89}$ Sjöstrand et al. op. cit., p. 717.

${ }^{90}$ Coggon \& Miola op. cit., pp. 533-5.

${ }^{91}$ Sjöstrand et al. op. cit., p. 718.

${ }^{92}$ Entwistle, Carter, Cribb et al. op. cit.

${ }^{93}$ I am immensely grateful to the third anonymous reviewer for raising this point.

${ }^{94}$ Mackenzie op. cit., p. 525.

${ }^{95}$ Mackenzie op. cit., pp. 518-9.

${ }^{96}$ Mackenzie op. cit., p. 514.

${ }^{97}$ Entwistle, Carter, Cribb et al. op. cit.; Elwyn, Frosch, Thomson et al. op. cit.; Wennberg op cit.; Dive on. cit.; Ubel, Scherr \& Fagerlin op. cit.; van Nistelrooij et al. op. cit.

${ }^{98}$ Mackenzie op. cit., p. 528.

${ }^{99}$ Mackenzie op. cit., p. 528.

${ }^{100}$ Mackenzie op. cit., pp. 527-8.

${ }^{101}$ I'd like to thank the third anonymous reviewer for making me aware of the fact that my observations concerning the tensions between the norms of SDM and the requirements of respect for 
autonomy can also be used to make sense of some of the limits and limitations of substantive theories of autonomy.

${ }^{102}$ For examples of some of the debates concerning substantive theories of autonomy, see Stoljar 2000 op. cit.; Marilyn Friedman, Autonomy, Gender, Politics (Oxford: Oxford University Press, 2003); Christman 2004 op. cit.; Benson 2005 op. cit.; Mackenzie op. cit.; Christman 2009 op. cit.; Suzy Killmister, 'Autonomy, liberalism and anti-perfectionism', Res Publica 19 (2013): 353-69; Meyers 2014 op. cit.; Natalie Stoljar, 'Relational autonomy and perfectionism', Moral Philosophy and Politics 4,1 (2017): 27-41. 